\title{
Oftalmopatia Tiroideia Severa e Tiroidite de Hashimoto, em Doente Eutiroideu
}

\author{
Severe Thyroid-associated Ophtalmopathy and \\ Hashimoto's Thyroiditis in Euthyroid Patient
}

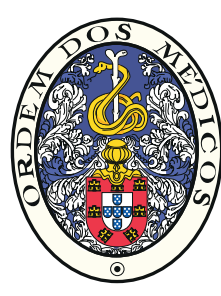

Raquel ESPÍRITO SANTO $\triangle^{1}$, Teresa SABINO ${ }^{1}$, Ana AGAPITO ${ }^{1}$

Acta Med Port 2016 Sep;29(9):572-572 - http://dx.doi.org/10.20344/amp.7015

Palavras-chave: Doença de Hashimoto; Hormonas Tiroideas; Oftalmopatia de Graves.

Keywords: Graves Ophthalmopathy; Hashimoto Disease; Hashimoto's thyroiditis; Thyroid Hormones.

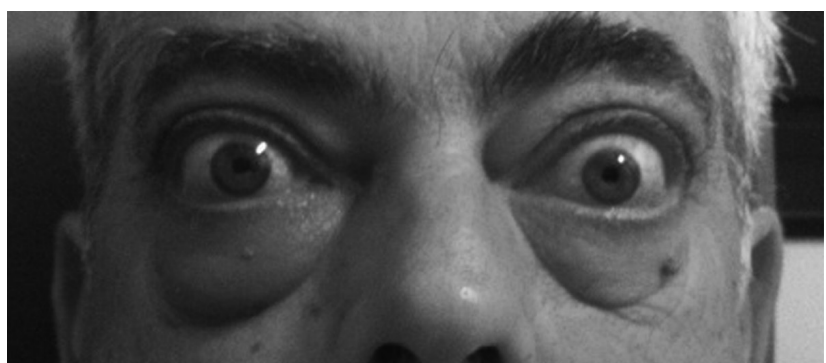

Figura 1 - Protrusão bilateral dos globos oculares

Indivíduo do sexo masculino, 50 anos, observado por oftalmopatia endócrina. Por diplopia e exoftalmia (Fig. 1), realizou TC orbitária que revelou espessamento dos músculos oculares extrínsecos, hipertrofia do tecido adiposo intraorbitário, exoftalmia bilateral e simétrica, aspetos evocadores de oftalmopatia endócrina tiroideia (Fig. 2). Avaliação clínica e laboratorial em eutiroidismo, com alterações sugestivas de tiroidite de Hashimoto (TSH 2,45 mUI/L [0,35 - 5,5], FT4 0,96 ng/dL [0,89 - 1,76], Ac-antiperoxidase 4 $203 \mathrm{UI} / \mathrm{mL}[<35]$, Ac-antitireoglobulina $22035 \mathrm{UI} / \mathrm{mL}[<$ 40] e TRAb < $1 \mathrm{U} / \mathrm{L})$. Instituída corticoterapia endovenosa e posterior cirurgia descompressiva orbitária bilateral. No follow-up (30 meses) manteve eutiroidismo. A oftalmopatia tiroideia é a causa mais comum de orbitopatia na população adulta e em $90 \%$ dos casos associa-se a doença de Graves. ${ }^{1,2}$ São raros os casos descritos de oftalmopatia tiroideia severa associada a tiroidite de Hashimoto,

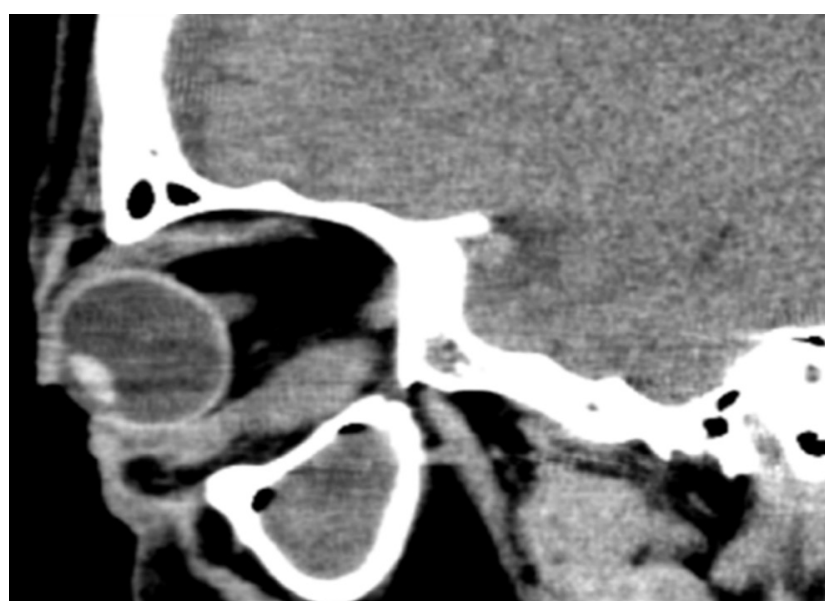

Figura 2 - Tomografia computorizada das órbitas revela espessamento dos músculos oculares extrínsecos, hipertrofia do tecido adiposo intraorbitário, exoftalmia bilateral e simétrica, sem anomalias do calibre dos nervos ópticos

podendo ser explicada pela produção de anticorpos dirigidos a antigénios periorbitários que não o receptor-TSH. ${ }^{3-4}$ A oftalmopatia tiroideia poderá preceder a disfunção tiroideia, justificando a vigilância deste doente.

\section{OBSERVAÇÕES}

Trabalho apresentado no âmbito do Congresso Nacional de Endocrinologia, que decorreu de 22 a 25 de janeiro de 2015 no Funchal, Madeira.

\section{REFERÊNCIAS}

1. Alves M, Neves C, Carvalho D, Medina JL. Abordagem da orbitopatia associada à tiróide. Acta Med Port. 2011;24:1041-50.

2. Metello JL, Gonzalez M, Eusébio R, Rocha V. Oftalmopatia associada à tiroide. Acta Med Port. 2004;17:329-34.

3. Ponto KA, Binder H, Diana T, Matheis N, Otto AF, Pitz S, et al. Prevalence, phenotype, and psychosocial well-being in euthyroid/hypothyroid thyroidassociated orbitopathy. Thyroid. 2015;25:942-8.

4. Yoshihara A, Noh JY, Nakachi A, Ohye H, Sato S, Sekiya K, et al. Severe thyroid-associated orbitopathy in Hashimoto's thyroiditis: report of 2 cases. Endocr J. 2011;58:343-8.

\footnotetext{
1. Serviço de Endocrinologia, Diabetes e Metabolismo. Hospital Curry Cabral. Centro Hospitalar de Lisboa Central. Lisboa. Portugal.

$\square$ Autor correspondente: Raquel Espírito Santo. anaraquel.ces@gmail.com

Recebido: 23 de setembro de 2015 - Aceite: 08 de janeiro de 2016 | Copyright @ Ordem dos Médicos 2016
} 